\title{
Aplicação de microrganismos endofíticos na agricultura e na produção de substâncias de interesse econômico
}

\section{Application endophytic microorganisms in agriculture and production of substances of economic interest}

\author{
Taides Tavares dos Santos ${ }^{1}$; Maurilio Antonio Varavallo ${ }^{2}$
}

\begin{abstract}
Resumo
Os microrganismos que vivem no interior de plantas e habitam de modo geral suas partes aéreas, como folhas e caules, mas não causam aparentemente nenhum dano a seus hospedeiros, são chamados de endofíticos. Além de exercerem diversas funções de importância para o hospedeiro, esses microrganismos são potencialmente úteis na agricultura e na indústria, sobretudo na farmacêutica e de defensivos agrícolas. Por se constituírem em potenciais substitutos de produtos químicos, ao exercerem ações de biocontrole e/ou promoção de crescimento de plantas, favorecendo a preservação do ambiente, vem sendo apontados como alternativa viável para sistemas de produção agrícola ecológica e economicamente sustentáveis. A obtenção de substâncias de interesse econômico, como enzimas, antibióticos e outros fármacos, a partir de microrganismos endofíticos, tem sido frequentemente relatada na literatura científica. Exemplo disso é o taxol, poderoso anticancerígeno que anteriormente era obtido apenas da exploração da planta Taxus brevifolia e, agora pode ser obtido de diferentes gêneros de fungos endofíticos. Avanços como este reforçam a grande potencialidade biotecnológica de tais microrganismos. Este trabalho visa apresentar um panorama sobre potenciais aplicações de microrganismos endofíticos na agricultura e na produção de substâncias de interesse econômico.
\end{abstract}

Palavras-chave: Bactérias endofíticas. Controle biológico. Fungos endofíticos. Promoção de crescimento de plantas. Substâncias de interesse econômico.

\begin{abstract}
Endophytic microorganisms are mainly fungi and bacteria that live inside plants, generally inhabiting aerial parts such as leaves and stems, without causing any apparent damage to their hosts. In addition to many important functions for the host, the endophytic microorganisms are potentially useful in agriculture and industry, especially in pharmaceuticals and agrochemicals. By forming themselves into substitutes for chemicals by exercising stock biocontrol and/or promotion of plant growth, favoring the environmental preservation, has been appointed as a viable alternative agricultural production systems for environmentally and economically sustainable. Obtaining substances of economic interest, such as enzymes, antibiotics and other drugs from endophytic microorganisms has often been reported in the scientific literature. One example is taxol, a powerful anti-cancer substance that was previously obtained only from the exploitation of the plant Taxus brevifolia, and can now be obtained from different genera of endophytic fungi. Advances like this reinforce the great biotechnological potential of such microorganisms. This study presents an overview of potential applications of endophytic microorganisms in agriculture and production of substances of economic interest.

Keywords: Endophytic bacteria. Biological control. Fungal endophytes. Promoting the growth of plants. Substances of economic interest.
\end{abstract}

1 Instituto Tocantinense Presidente Antônio Carlos (ITPAC), Araguaína, TO, Brasil, Discente de Farmácia Generalista. E-mail: taides.tavares@hotmail.com.

2 Universidade Federal do Tocantins (UFT), Campus de Gurupi, TO, Brasil. Professor Adjunto, graduado em Ciências Biológicas pela Universidade Estadual de Londrina, mestre e doutor em Microbiologia Agrícola pela Universidade Federal de Viçosa. E-mail: varavallo@uft.edu.br 


\section{Introdução}

Complexos

mecanismos

adaptativos, evolutivamente, vêm sendo desenvolvidos pelas plantas; muitos deles somente são possíveis graças às interações com os microrganismos, dos quais se destacam os endofíticos (PEIXOTO NETO; AZEVEDO; CAETANO, 2004). Eles foram mencionados pela primeira vez no início do século XIX, entretanto, foi apenas no final dos anos 70 do século $\mathrm{XX}$, que eles começaram a ser tratados com maior ênfase em trabalhos científicos. Estudos demonstraram que esses microrganismos possuem funções importantes para seus hospedeiros, pois apresentam interações simbióticas com o mesmo, e são capazes de proteger as plantas do ataque de insetos, de doenças e do ataque de mamíferos herbívoros por meio da produção de toxinas (AZEVEDO, 1998; AZEVEDO, 1999; AZEVEDO et al., 2000; PEIXOTO NETO; AZEVEDO; ARAÚJO, 2002).

Os microrganismos endofíticos incluem principalmente fungos e bactérias que vivem no interior das plantas, habitando de modo geral suas partes aéreas, como folhas e caules, sem causar aparentemente nenhum dano a seus hospedeiros (AZEVEDO, 1998; PEIXOTO NETO; AZEVEDO; ARAÚJO, 2002; PEIXOTO NETO; AZEVEDO; CAETANO, 2004; ASSUMPÇÃO et al., 2009). Isso os diferencia dos microrganismos fitopatogênicos, que são prejudiciais às plantas e causam-lhes doenças. Eles são também distintos dos microrganismos epifíticos, que vivem na superfície dos órgãos e tecidos vegetais (AZEVEDO, 1998; SOUZA et al., 2004).

Os microrganismos endofíticos são potencialmente úteis à agricultura e à indústria, particularmente na alimentícia e farmacêutica; várias espécies selecionadas de endófitos apresentam potencial de emprego nas indústrias de defensivos agrícolas, além de serem utilizadas como vetores genéticos (VERZIGNASSI; HOMECHIN; VIDA, 1996; SOUZA et al., 2004).
Os microrganismos endofíticos podem produzir toxinas, antibióticos e outros fármacos, fatores de crescimento e muitos outros produtos de potencial interesse biotecnológico, além de exercerem outras funções de importância para o hospedeiro, tais como a maior resistência às condições de estresse, à alteração de propriedades fisiológicas e à produção de fitohormônios (AZEVEDO, 1998; AZEVEDO et al., 2000).

$\mathrm{O}$ interesse no emprego de microrganismos em práticas agrícolas aumentou significativamente nos últimos anos, pois tanto na promoção de crescimento vegetal como no controle biológico de pragas e doenças de plantas entre outras aplicações, eles se constituem em potenciais substitutos de produtos químicos, podendo favorecer desta maneira a preservação do ambiente (SOUZA, 2001; PEIXOTO NETO; AZEVEDO; ARAÚJO, 2002). Dentro desse contexto, os microrganismos apresentam importante propriedade de conferir proteção às plantas, seja pela sua presença nas plantas hospedeiras, seja pela aplicação como agentes de biocontrole, que podem resultar na eliminação de pragas agrícolas (SOUZA, 2001). Por isso, tem havido um crescente interesse no estudo da ocorrência, do potencial de colonização e da utilização de bactérias endofíticas, e outros endófitos, para a promoção de crescimento e controle biológico de doenças de plantas (MARIANO et al., 2004).

O presente trabalho apresenta um panorama sobre potenciais aplicações de microrganismos endofíticos na agricultura e na produção de substâncias de interesse econômico.

\section{Interação entre microrganismos endofíticos e seus hospedeiros}

Geralmente, bactérias e fungos endofíticos desempenham funções importantes no processo de adaptação da planta ao meio. Embora possam ser confundidos com patógenos latentes, estudos têm demonstrado que, em muitos casos, existe uma importante interação simbiótica com o hospedeiro, 
a qual envolve a produção de compostos que diminuem a herbivoria sobre os tecidos vegetais ou conferem resistência a fitopatógenos, além da produção de fitoreguladores que podem aumentar o desenvolvimento vegetal, entre outros. Por sua vez, os endófitos encontram na planta um habitat com nutrientes e com menor competição com outros microrganismos (PEIXOTO NETO; AZEVEDO; CAETANO, 2004).

Em geral, os microrganismos endofíticos adentram as plantas por aberturas naturais e ferimentos. Uma das portas de entrada mais utilizadas pelos endófitos são as raízes; a emergência de raízes laterais resulta em uma abertura, que serve de entrada para os microrganismos. O próprio crescimento das raízes, ao penetrar no solo, gera abrasões que facilitam a entrada de microrganismos. Outras portas de entrada são aberturas naturais como estômatos e hidatódios, aberturas causadas por insetos, e até por estruturas de fungos patogênicos, como os apressórios (AZEVEDO, 1998).

De modo geral, as plantas possuem uma microbiota endofítica característica, importante para sua sanidade e manutenção (AZEVEDO, 1999). Alguns fatores interferem qualitativa $\mathrm{e}$ quantitativamente na biodiversidade da microbiota dos endofíticos. Destacam-se a idade da planta, o tecido ou órgão da planta, além do tempo gasto até as plantas ou suas partes serem submetidas ao isolamento dos endófitos (PEIXOTO NETO; AZEVEDO; CAETANO, 2004). Como uma mesma planta pode possuir microrganismos epifíticos e patogênicos além dos endofíticos, o isolamento desses últimos deve ser feito a partir do interior de tecidos e órgãos sadios, evitando-se, assim, os microrganismos patogênicos. Deve ser feita também a desinfecção da superfície do fragmento da planta, eliminando-se, dessa forma, os microrganismos epifíticos (PEIXOTO NETO; AZEVEDO; ARAÚJO, 2002).

$\mathrm{O}$ estudo das interações entre plantas e microrganismos, além de contribuir grandemente para o entendimento de muitos processos químicos e ecológicos, pode resultar no estabelecimento de fontes alternativas de substâncias de interesse para a Humanidade (SANTOS et al., 2008), tais como substâncias detentoras de ação farmacológica, enzimas, e muitos outros produtos de potencial emprego na agricultura e nas indústrias alimentícia, farmacêutica e química.

\section{Aplicação de microrganismos endofíticos em controle biológico de patogenias}

Há tempos, os pesticidas químicos têm sido usados na agricultura (GRIGOLETTI JUNIOR; SANTOS; AUER, 2000), porém, além de seus riscos para a saúde humana, também causam fortes desequilíbrios no ambiente, destruindo os inimigos naturais das diferentes pragas de culturas nas áreas em que são utilizados (MEDEIROS; VILELA; FRANÇA, 2006). O controle químico pode causar danos na microbiota benéfica das plantas, além de frequentemente deixar resíduos no ambiente (ETHUR et al., 2007) e nos alimentos.

O controle de doenças bacterianas em plantas tem a limitação quanto à disponibilidade de produtos químicos; nesse caso, são usados apenas alguns poucos antibióticos, além de outros produtos de ação bactericida ou de indução de resistência (SILVA et al., 2008); o ideal seria empregar produtos de baixa toxicidade no controle dessas doenças, visando à minimização dos danos ao ambiente.

A utilização de microrganismos com ação de biocontrole e/ou promoção de crescimento vem sendo apontada como alternativa viável para sistemas de produção agrícola ecológica e economicamente sustentáveis (COMPANT et al., 2005; SOUSA; SOARES; GARRIDO, 2009), e o controle biológico através de antagonistas tem possibilitado solução viável para várias doenças consideradas de difícil controle (MOURA; ROMEIRO; NEVES, 1998). O controle biológico de fitobactérias vem recebendo bastante atenção, por se tratar de um método natural, sem causar impactos ao ambiente e efeitos 
toxicológicos (SILVA et al., 2008).

O controle biológico visa a manter, mediante certas práticas, um equilíbrio no agroecossistema, de modo que o hospedeiro, na presença do patógeno, não sofra danos significativos, em função da ação controladora exercida pelos organismos não patogênicos no sistema (GRIGOLETTI JUNIOR; SANTOS; AUER, 2000). Essa ação controladora pode ocorrer através de diversos mecanismos, tais como a produção de ácido cianídrico, bacteriocinas e antibióticos, competição por espaço, $\mathrm{Fe}^{+3}$ e outros nutrientes, parasitismo, indução de resistência e proteção cruzada (MARIANO et al., 2004).

A diversidade de microrganismos que uma planta hospeda, bem como suas relações antagônicas, surgem como ferramentas importantes para o controle biológico aplicado (LANNA FILHO; FERRO; PINHO, 2010). Exemplificando-se, poderia se utilizar no controle de determinada patogenia, um microrganismo não patogênico com necessidades nutricionais semelhantes as do patógeno, para promover uma competição por nutrientes e espaço físico e, consequente controle da disseminação da enfermidade. Outra possível aplicação poderia ser embasada na capacidade que determinados microrganismos possuem de produzir substâncias com ação antibiótica.

Estudos enfocando a aplicação de microrganismos endofíticos em controle biológico, tanto de patogenias de origem fúngica como bacteriana, têm sido desenvolvidos e, resultados promissores têm sido apresentados, comprovando o potencial que esses microrganismos possuem. No entanto, mesmo apresentando-se em trabalhos científicos como alternativas viáveis aos inseticidas químicos, muito ainda precisa ser feito para que esses microrganismos de fato sejam empregados. Entre os esforços necessários, mencionam-se a reprodução no campo dos resultados obtidos em estudos científicos, avaliando-se a influência de fatores externos, como as condições climáticas específicas de cada região e a interação com outras espécies vegetais que ocorrem no mesmo local, entre outros interferentes. É necessário determinar também o modo de ação desses microrganismos, a quantidade de endófitos que deve ser aplicada e, as melhoras formas de entrada no hospedeiro (STURTZ; MATHESON, 1996; BENCHIMOL et al., 2000; RUBINI et al., 2005; OLIVEIRA et al., 2006; SHIOMI et al., 2006; SHIOMI; MELO; MINHONI, 2008; SILVA et al., 2008; BARRETTI et al., 2009; ROCHA et al., 2009); assim sendo, a continuidade e a intensificação de estudos nessa área é imprescindível.

\section{Bactérias endofíticas em controle biológico de patogenias}

Benchimol et al. (2000) testaram o efeito de bactérias endofíticas isoladas de plântulas de pimenta-do-reino na redução da mortalidade causada por fusariose, enfermidade provocada pelo fungo Fusarium solani, e detectaram que a espécie Methylobacterium radiotolerans controlou o patógeno, causando redução significativa do número de plantas mortas (BENCHIMOL et al., 2000).

No trabalho de Shiomi et al. (2006), foram selecionados isolados de bactérias endofíticas de folhas e ramos de cafeeiro com potencial para o controle biológico da ferrugem do cafeeiro, causada pelo fungo Hemileia vastatrix. Alguns isolados foram eficientes em controlar a ferrugem do cafeeiro, embora outros tenham aumentado a severidade da doença (SHIOMI et al., 2006).

Silva et al. (2008) selecionaram isolados de bactérias endofíticas de diferentes espécies e gêneros obtidos de folhas e haste de tomateiro e pimentão para o controle da pinta bacteriana (Pseudomonas syringae) do tomateiro; as espécies bacterianas mais eficazes na redução da severidade da pinta bacteriana foram Acinetobacter johnsonii, Bacillus pumilus, Paenibacillus macerans, Bacillus sphaericus, B. amyloliquefaciens e Staphylococcus aureus. Mais de 50\% dos isolados eficazes na 
redução da severidade foram da espécie Bacillus pumilus (SILVA et al., 2008).

No trabalho de Barretti et al. (2009), quarenta isolados bacterianos endofíticos de plantas sadias de tomateiro foram avaliados quanto à sua potencialidade como agentes de biocontrole de enfermidades bacteriana e fúngica do tomateiro. Uma seleção massal foi realizada em casa de vegetação, utilizando-se Pseudomonas syringae e Alternaria solani, como patógenos desafiantes; com base na média do número de lesões por planta, quatro isolados foram selecionados como potenciais agentes de biocontrole, identificados como Acinetobacter johnsonii, Serratia marcescens, Sinorhizobium sp. e Bacillus megaterium (BARRETTI et al., 2009).

\section{Fungos endofíticos em controle biológico de patogenias}

Rubini et al. (2005), a fim de avaliar o potencial de endófitos no controle biológico do fungo Crinipellis perniciosa, agente da enfermidade vassourade-bruxa do cacau, estudaram a comunidade de fungos endofíticos de plantas de cacau resistentes e suscetíveis à enfermidade. Os fungos isolados foram identificados e avaliados in vitro e in vivo pela habilidade de inibir o patógeno. Entre os fungos avaliados, Gliocladium catenulatum reduziu a incidência da doença em 70\% (RUBINI et al., 2005).

Rocha et al. (2009) selecionaram linhagens endofíticas isoladas de folhas de confrei, com potencial de antagonismo in vitro contra a linhagem fitopatogênica Sclerotinia sclerotiorum, agente do mofo branco, que causa danos em culturas de feijão. Doze linhagens de fungos endofíticos foram utilizadas na técnica de desafio em placa contra um isolado patogênico de $S$. sclerotiorum e, quatro linhagens com melhor atividade antagonística foram selecionadas. Zonas de inibição no crescimento da linhagem patogênica foram consideradas como indicativo de antibiose. Foram efetuadas análises da porcentagem de elongação micelial com e sem antagonismo, mostrando resultados de 46,7\% a $50,0 \%$ de redução no crescimento micelial do fitopatógeno (ROCHA et al., 2009).

\section{Aplicação de microrganismos endofíticos em promoção de crescimento de plantas}

Uma agricultura sustentável requer a utilização de estratégias que permitam o aumento da produção de alimentos sem prejuízo ao meio ambiente e saúde, dentro do contexto econômico, social e político de cada região (MARIANO et al., 2004). A utilização de microrganismos promotores de crescimento vegetal é uma das alternativas para a agricultura moderna enfrentar o desafio de promover o aumento da produção de culturas gerando sustentabilidade. Entre esses microrganismos, encontram-se os endofíticos (LUZ et al., 2006).

Essa capacidade de estimular o crescimento vegetal apresentada pelos microrganismos endofíticos tem sido atribuída a mecanismos diretos tais como fixação do nitrogênio e produção de fitohormônios, e indiretos como antagonismo a fitopatógenos (PEIXOTO NETO; AZEVEDO; ARAÚJO, 2002; LUZ et al., 2006). Na maioria dos gêneros de bactérias endofíticas, a produção de auxinas, etileno e citocininas, o aumento da absorção de água e nutrientes bem como a supressão de microrganismos deletérios são responsáveis pela promoção de crescimento da planta (MARIANO et al., 2004).

Estudos envolvendo microrganismos endofíticos na promoção de crescimento de plantas no Brasil já foram desenvolvidos com milho (Zea mays) e fumo (Nicotiana tabacum) (VARMA et al., 1999), hortelãpimenta (Mentha piperita) (MUCCIARELLI et al., 2003), maracujazeiro-amarelo (Passiflora edulis) (LUZ etal., 2006), pinha (Annona squamosa) (SILVA et al., 2006), tomateiro (Solanum lycopersicum) (BARRETTI et al., 2008; BARRETTI; SOUZA; POZZA, 2008) e abacaxizeiro (Ananas comosus) (BALDOTTO et al., 2010), apresentando respostas promissoras. 
As bactérias endofíticas dos gêneros Acetobacter, Acinetobacter, Actinomyces, Agrobacterium, Azospirillum, Bacillus, Burkholderia, Curtobacterium, Pantoea, Pseudomonas e Xanthomonas, entre outros, têm sido freqüentemente utilizadas em promoção de crescimento de plantas. Além das bactérias, os fungos endofíticos também podem promover o crescimento vegetal; entre as espécies mais estudadas está Piriformospora indica, um basidiomiceto que coloniza endofiticamente raízes de inúmeras espécies vegetais, aumentando o seu crescimento (PEIXOTO NETO; AZEVEDO; ARAÚJO, 2002).

\section{Produção de substâncias de interesse econômico por microrganismos endofíticos}

Os fungos e outros microrganismos têm sido bastante utilizados como produtores de diferentes substâncias de interesse econômico, tais como enzimas, antibióticos, vitaminas, aminoácidos e esteróides (BRAGA; DESTÉFANO; MESSIAS, 1999).

É notável que, dentre as quase 300.000 espécies de plantas que existem na Terra, cada indivíduo é hospedeiro de um ou vários microrganismos endofíticos (STROBEL; DAISY, 2003). Somente algumas dessas plantas já foram completamente estudadas quanto à sua biologia endofítica. Conseqüentemente, a oportunidade de encontrar microrganismos endofíticos novos e com potencial de utilização entre as plantas que compõem os diferentes ecossistemas é grande (STROBEL; DAISY, 2003; RYAN et al., 2008).

Os microrganismos endofíticos são potenciais fontes de produtos naturais, bioativos equimicamente novos, para a exploração na medicina, na agricultura e na indústria (STROBEL; DAISY, 2003; TEJESVI et al., 2007). Eles podem ser utilizados como fontes de metabólitos primários (STAMFORD; ARAÚJO; STAMFORD, 1998; CARRIM; BARBOSA; VIEIRA, 2006) e secundários de interesse econômico como o taxol, poderoso anticancerígeno (LI et al., 1996; STROBEL et al., 1996; WANG et al., 2000; GUO et al., 2006; GANGADEVI; MUTHUMARY, 2008, 2009; SREEKANTH et al., 2009; VISALAKCHI; MUTHUMARY, 2010).

O trabalho desenvolvido por Carrim, Barbosa e Vieira (2006) exemplifica a produção de metabólitos primários de interesse econômico. Eles isolaram bactérias endofíticas de Jacaranda decurrens e selecionaram enzimas de interesse biotecnológico. Dez espécies de bactérias foram isoladas e identificadas; todas apresentaram atividade enzimática, com maior predominância de atividade proteolítica e amilolítica, seguidas das atividades lipolítica e esterásica (CARRIM; BARBOSA; VIEIRA, 2006). Essas enzimas produzidas por microrganismos apresentam potencial de aplicabilidade em diversos campos, como no processamento de alimentos, na fabricação de detergentes, de tecidos, de produtos farmacêuticos, na terapia médica e na biologia molecular (STAMFORD; ARAÚJO; STAMFORD, 1998; CARRIM; BARBOSA; VIEIRA, 2006).

\section{Produção de Taxol por fungos endofíticos}

A produção de taxol por um microrganismo endofítico foi demonstrada pela primeira vez através dos estudos de Stierle, Strobel e Stierle (1993), onde se evidenciou que o fungo endofítico Taxomyces andreanea, encontrado no interior da planta Taxus brevifolia, era capaz de produzir taxol (STIERLE; STROBEL; STIERLE, 1993).

Trabalhos posteriores demonstraram que diferentes espécies de fungos endofíticos produzem taxol. É o caso de Pestalotiopsis microspora, isolado de Taxus wallachiana (STROBEL et al., 1996), Tubercularia sp., isolado de Taxus mairei (WANG et al., 2000), Colletotrichum gloeosporioides, isolado de Justicia gendarussa (GANGADEVI; MUTHUMARY, 2008), Pestalotiopsis terminaliae, isolado de Terminalia arjuna (GANGADEVI; MUTHUMARY, 2009), Gliocladium sp., isolado de 
Taxus baccata (SREEKANTH et al., 2009), entre outras.

Relatos como o do taxol, inicialmente isolado de Taxus brevifolia e, em seguida, de diversos endófitos desta e de outras plantas que o produzem, sugerem um relacionamento entre planta e microrganismo que deve ser melhor explorado (SOUZA et al., 2004).

Com a descoberta de que fungos endofíticos podem também produzir o taxol, visualizou-se um novo processo talvez mais eficiente e menos dispendioso para a produção deste importante fármaco, que seria o cultivo de fungos em laboratório, dispensando a necessidade de exploração de Taxus brevifolia ou de outras espécies vegetais produtoras (PEIXOTO NETO; AZEVEDO; ARAÚJO, 2002). Essa é a vantagem da prospecção química de metabólitos fúngicos em relação às demais fontes, pois os microrganismos podem ser cultivados em larga escala em fermentadores, e não geram prejuízo ao ecossistema, como pode ocorrer com a retirada de plantas de áreas naturais (TAKAHASHI; LUCAS, 2008). Minimiza-se, dessa forma, o perigo de extinção de algumas espécies vegetais, que são coletadas para a extração de produtos medicinais (PEIXOTO NETO; AZEVEDO; ARAÚJO, 2002).

\section{Produção por microrganismos endofíticos de compostos bioativos com potenciais aplicações como agentes antimicrobianos}

Estudos com o intuito de avaliar a atividade biológica de microrganismos endofíticos, a fim de se obter novos compostos bioativos vêm sendo conduzidos e resultados muito promissores têm sido alcançados (STROBEL et al., 2001; SOUZA et al., 2004; PHONGPAICHIT et al., 2006; FERNANDES et al., 2009; MELO et al., 2009; DING et al., 2010; LV et al., 2010; RAMOS et al., 2010; ROSA et al., 2010).

Dentre os microrganismos que acumulam substâncias antifúngicas, fungos e leveduras destacam-se pela quantidade de produtos farmacêuticos de uso corrente na medicina com tais propriedades (CAFÊU et al., 2005). Dessa forma, os fungos endofíticos apresentam-se como uma fonte alternativa para a produção de novos agentes antimicrobianos (FERNANDES et al., 2009). Como exemplo, pode-se citar a produção de criptocandina, um lipopeptídeo antimicótico, pelo fungo endofítico Cryptosporiopsis quercina (STROBEL et al., 1999). Souza et al. (2004) avaliaram a atividade antimicrobiana de fungos endofíticos isolados de plantas da Amazônia, Palicourea longiflora e Strychnos cogens (SOUZA et al., 2004). Cafêu et al. (2005) identificaram a produção de substâncias antifúngicas por Xylaria sp., fungo endofítico isolado de Palicourea marcgravii (CAFÊU et al., 2005).

\section{Outros metabólitos secundários de interesse produzidos por fungos endofíticos}

Além da produção de taxol, tem-se relatado na literatura científica a produção de diversos outros metabólitos secundários de interesse econômico por fungos endofíticos, demonstrando as potencialidades biotecnológicas de tais microrganismos (MARINHO et al., 2005; BORGES; PUPO, 2006; MARINHO; MARINHO; RODRIGUES FILHO, 2007; MOMESSO et al., 2008; MARINHO; MARINHO; RODRIGUES FILHO, 2009; ARUNPANICHLERT et al., 2010; SILVA et al., 2010). A seguir são descritos alguns exemplos:

a) Produção de diferentes policetídeos por Penicillium janthinellum, fungo endofítico isolado dos frutos de Melia azedarach (MARINHO et al., 2005), por Phoma sorghina, fungo endofítico associado à Tithonia diversifolia (BORGES; PUPO, 2006) e por outras espécies de Penicillium isoladas de Melia azedarach e de Murraya paniculata (PASTRE et al., 2007). Os policetídeos constituem uma grande classe de metabólitos secundários que apresentam uma das maiores diversidades estruturais entre os produtos 
naturais e a maioria desses compostos é ativa em diversos sistemas biológicos. Por isso, a busca dessas substâncias em microrganismos vem sendo apontada como uma boa estratégia para pesquisas de substâncias bioativas (MARINHO et al., 2005; BORGES; PUPO, 2006; PASTRE et al., 2007).

b) Produção de citocalasinas, substâncias que apresentam diversas atividades biológicas incluindo ação citotóxica, por Chaetomium globosum, fungo endofítico associado à Viguiera robusta (MOMESSO et al., 2008) e por Xylaria sp., fungo endofítico associado a Piper aduncum (SILVA et al., 2010).

c) Produção de 2,4-diidroxi-5,6-dimetil benzoato de etila e phomopsilactona, compostos com atividades antifúngica e citotóxica, por Phomopsis cassiae, fungo endofítico de Cassia spectabilis (SILVA et al., 2005).

d) Produção de muitos outros metabólitos secundários com importantes atividades biológicas e potencial de aplicação na indústria farmacêutica e química, como esteróides por Penicillium herquei, fungo endofítico isolado dos frutos de Melia azedarach (MARINHO; MARINHO; RODRIGUES FILHO, 2009); ergosterol, peróxido de ergosterol, cerivisterol, uracila e dulcitol, por Penicillium sp., fungo endofítico isolado de Murraya paniculata (MARINHO; MARINHO; RODRIGUES FILHO, 2007); sesquiterpenos por Xylaria sp., fungo endofítico isolado dos tecidos sadios das folhas de Cupressus lusitanica (AMARAL; RODRIGUES-FILHO, 2010).

A existência de endófitos tem sido observada em inúmeras espécies de plantas medicinais, estando muitas vezes envolvidos em complexas relações de síntese, acúmulo e degradação de metabólitos secundários de interesse econômico (PEIXOTO NETO; AZEVEDO; CAETANO, 2004). Do ponto de vista ecológico, é extremamente importante a descoberta de fontes microbianas produtoras de fármacos de alto valor agregado, porém produzidos em quantidades reduzidas por espécies vegetais. Estas, devido ao extrativismo predatório estão ameaçadas de extinção. Os endófitos apresentamse como uma perspectiva muito importante para garantir a preservação destas espécies, mantendo a produção de compostos que garantam a vida de pessoas afetadas por inúmeras doenças (PEIXOTO NETO; AZEVEDO; ARAÚJO, 2002).

\section{Outras potenciais aplicações de microrganismos endofíticos}

Pesquisas têm demonstrado que microrganismos endofíticos podem influenciar na preferência e na performance de insetos herbívoros. As primeiras publicações com endofíticos demonstraram que a presença desses microrganismos resultava na diminuição dos danos causados por fitófagos (OKI et al., 2009). Trabalhos sobre a importância de microrganismos endofíticos na resistência ao ataque por insetos já foram publicados (RAPS; VIDAL, 1998; MEISTER et al., 2006). Consequentemente, aumenta ointeresse para ouso desses microrganismos no controle biológico de pragas e patógenos em práticas agrícolas (AZEVEDO et al., 2000).

Além de poderem ser potenciais promotores de crescimento de plantas ou agentes de controle biológico de patogenias, microrganismos endofíticos podem apresentar outros efeitos de importância em práticas agrícolas; alguns microrganismos endofíticos aumentam a tolerância de plantas à seca, enquanto outros promovem a fixação não simbiótica do nitrogênio atmosférico (AZEVEDO, 1998). Assumpção et al. (2009), ao avaliar o potencial biotecnológico da comunidade bacteriana endofítica de sementes de soja, detectaram que $18 \%$ dos isolados controlaram o crescimento de fungos fitopatogênicos, $100 \%$ produziram ácido indolacético (AIA), e 39\% solubilizaram fosfato (ASSUMPÇÃO et al., 2009). Kuss et al. (2007) avaliaram a fixação de nitrogênio e produção de AIA in vitro por bactérias diazotróficas endofíticas associadas a raízes de arroz (Oryza sativa) e, também obtiveram resultados promissores (KUSS et al., 2007).

Teixeira et al. (2007) realizaram um levantamento da diversidade de microrganismos endofíticos em 
plantas de mandioca(Manihot esculenta) e avaliaram seu potencial para fixar nitrogênio atmosférico e para produzir AIA; resultados satisfatórios foram obtidos. A ocorrência de bactérias endofíticas em plantas de mandioca com capacidade para fixar nitrogênio atmosférico e produzir AIA in vitro indica potencial para promover o crescimento da planta (TEIXEIRA et al., 2007).

Trabalhos recentes têm demonstrado que microrganismos endofíticos podem ser utilizados também como vetores para introdução de características de interesse biotecnólogico na planta. Assim, fungos e bactérias endofíticas poderiam ser alterados geneticamente e, expressando genes de interesse, serem utilizados para o controle de fitopatógenos, promoção de crescimento vegetal e síntese de vitaminas, aminoácidos, entre outros produtos de interesse (PEIXOTO NETO; AZEVEDO; CAETANO, 2004).

\section{Considerações finais}

Evidencia-se, por meio das publicações recentes, que as possibilidades de aplicações de microrganismos endofíticos vem aumentando e que, cada vez mais, têm se intensificado os estudos científicos objetivando comprovar a efetividade das mesmas.

Diversos trabalhos científicos têm demonstrado o potencial que microrganismos endofíticos possuem de promoverem crescimento e/ou controlarem patogenias em plantas; caso essa potencialidade fosse verdadeiramente aplicada em sistemas agrícolas, esses microrganismos seriam alternativas viáveis e baseadas em princípios ecológicos em substituição aos inseticidas e defensivos agrícolas.

O potencial de produção de substâncias de interesse econômico apresentado pelos microrganismos endofíticos é de relevância inquestionável, sobretudo para as indústrias farmacêutica, química e alimentícia. A produção de diversos metabólitos, tanto primários como secundários, foi relatada até agora e, com o incremento dos trabalhos de isolamento, identificação e exploração de microrganismos endofíticos, a tendência é aumentar ainda mais.

\section{Referências}

AMARAL, L. S.; RODRIGUES-FILHO, E. Two novel eremophilane sesquiterpenes from an endophytic Xylariaceous fungus isolated from leaves of Cupressus lusitanica. Journal of the Brazilian Chemical Society, São Paulo, v. 21, n. 8, p. 1446-1450, 2010.

ARUNPANICHLERT, J.; RUKACHAISIRIKUL,V.; SUKPONDMA, Y.; PHONGPAICHIT, S.; TEWTRAKUL, S.; RUNGJINDAMAI, N.; SAKAYAROJ, J. Azaphilone and isocoumarin derivatives from the endophytic fungus Penicillium sclerotiorum PSU-A13. Chemical \& Pharmaceutical Bulletin, Tokyo, v. 58, n. 8, p. 1033-1036, 2010.

ASSUMPÇÃO, L. C.; LAÇAVA, P. T.; DIAS, A. C. F.; AZEVEDO, J. L.; MENTEN, J. O. M. Diversidade e potencial biotecnológico da comunidade bacteriana endofítica de sementes de soja. Pesquisa Agropecuária Brasileira, Brasília, v. 44, n. 5, p. 503-510, 2009.

AZEVEDO, J. L. Botânica: uma ciência básica ou aplicada? Revista brasileira de Botânica, São Paulo, v. 22, n. 2, p. 225-229, 1999.

AZEVEDO, J. L. Microrganismos endofíticos. In: MELO, I. S.; AZEVEDO, J. L. (Ed.) Ecologia microbiana. Jaguariúna: EMBRAPA, 1998. p. 117-137.

AZEVEDO, J. L.; MACCHERONI JUNIOR, W.; PEREIRA, J. O.; ARAÚJO, W. L. Endophytic microorganisms: a review on insect control and recent advances on tropical plants. Electronic Journal of Biotechnology, Chile, v. 3, n. 1, p. 40-65, 2000.

BALDOTTO, L. E. B.; BALDOTTO, M. A.; OLIVARES, F. L.; VIANA, A. P.; BRESSAN-SMITH, R. Seleção de bactérias promotoras de crescimento no abacaxizeiro cultivar Vitória durante a aclimatização. Revista Brasileira de Ciência do Solo, Campinas, v. 34, n. 2, p. 349-360, 2010.

BARRETTI, P. B.; ROMEIRO, R. S.; MIZUBUTI, E. S. G.; SOUZA, J. T. Seleção de bactérias endofíticas de tomateiro como potenciais agentes de biocontrole e de promoção de crescimento. Ciência e Agrotecnologia, Lavras, v. 33, p. 2038-2044, 2009.

BARRETTI, P. B.; SOUZA, R. M.; POZZA, A. A. A.; POZZA, E. A.; CARVAlHO, J. G.; SOUZA, J. T. Aumento da eficiência nutricional de tomateiros 
inoculados com bactérias endofíticas promotoras de crescimento. Revista Brasileira de Ciência do Solo, Viçosa, v. 32, n. 4, p. 1541-1548, 2008.

BARRETTI, P. B.; SOUZA, R. M.; POZZA, E. A. Bactérias endofíticas como agentes promotores do crescimento de plantas de tomateiro e de inibição in vitro de Ralstonia solanacearum. Ciência agrotécnica, Lavras, v. 32, n. 3, p. 731-739, 2008.

BENCHIMOL, R. L.; CHU, E. Y.; YUITIMUTO, R.; DIAS-FILHO, M. B. Controle da fusariose em plantas de pimenta-do-reino com bactérias endofíticas: sobrevivência e respostas morfofisiológicas. Pesquisa Agropecuária Brasileira, Brasília, v. 35, n. 7, p. 13431348, 2000.

BORGES, W. S.; PUPO, M. T. Novel anthraquinone derivatives produced by Phoma sorghina, an endophyte found in association with the medicinal plant Tithonia diversifolia (Asteraceae). Journal of the Brazilian Chemical Society, São Paulo, v. 17, n. 5, p. 929-934, 2006.

BRAGA, G. U. L.; DESTÉFANO, R. H. R.; MESSIAS, C. L. Protease production during growth and autolysis of submerged Metarhizium anisopliae cultures. Revista de Microbiologia, São Paulo, v. 30, n. 2, p. 107-113, 1999.

CAFÊU, M. C.; SILVA, G. H.; TELES, H. L.; BOLZANI, V. S.; ARAÚJO, A. R.; YOUNG, M. C. M.; PFENNING, L. H. Substâncias antifúngicas de Xylaria sp., um fungo endofítico isolado de Palicourea marcgravii (Rubiaceae). Química Nova, São Paulo, v. 28, n. 6, p. 991-995, 2005.

CARRIM, A. J. I.; BARBOSA, E. C.; VIEIRA, J. D. G. Enzymatic activity of endophytic bacterial isolates of Jacaranda decurrens Cham. (Carobinha-do-campo). Brazilian Archives of Biology and Technology, Curitiba, v. 49, n. 3, p. 353-359, 2006.

COMPANT, S.; DUFFY, B.; NOWAK, J.; CLEMENT, C.; BARKA, E. A. Use of plant growth-promoting bacteria for biocontrol of plant diseases: principles, mechanisms of action, and future Prospects. Applied and Environmental Microbiology, Washington, v. 71, n. 9, p. 4951-4959, 2005.

DING, T.; JIANG, T.; ZHOU, J.; XU, L.; GAO, Z. M. Evaluation of antimicrobial activity of endophytic fungi from Camptotheca acuminata (Nyssaceae). Genetics and Molecular Research, Ribeirão Preto, v. 9, n. 4, p. 21042112, 2010.

ETHUR, L. Z.; BLUME, E.; MUNIZ, M. F. B.; FLORES, M. G. V. Seleção de antagonistas fúngicos a Fusarium solani e Fusarium oxysporum em substrato comercial para mudas. Ciência Rural, Santa Maria, v. 37, n. 6, p. 1794-1797, 2007.
FERNANDES, M. R. V.; SILVA, T. A. C.; PFENNING, L. H.; COSTA-NETO, C. M.; HEINRICH, T. A.; ALENCAR, S. M.; LIMA, M. A.; IKEGAKI, M. Biological activities of the fermentation extract of the endophytic fungus Alternaria alternata isolated from Coffea arabica L. Brazilian Journal of Pharmaceutical Sciences, São Paulo, v. 45, n. 4, p. 677-685, 2009.

GANGADEVI, V.; MUTHUMARY, J. Isolation of Colletotrichum gloeosporioides, a novel endophytic taxol-producing fungus from the leaves of a medicinal plant, Justicia gendarussa. Mycologia Balcanica, Bulgária, v. 5, p. 1-4, 2008.

GANGADEVI, V.; MUTHUMARY, J. Taxol production by Pestalotiopsis terminaliae, an endophytic fungus of Terminalia arjuna (arjun tree). Biotechnology and Applied Biochemistry, v. 52, p. 9-15, 2009.

GRIGOLETTI JUNIOR, A.; SANTOS, A. F.; AUER, C. G. Perspectivas do uso do controle biológico contra doenças florestais. Floresta, v. 30, n. 0, p. 155-165, 2000.

GUO, B. H.; WANG, Y. C.; ZHOU, X. W.; HU, K.; TAN, F.; MIAO, Z. Q.; TANG, K. X. An endophytic Taxolproducing fungus BT2 isolated from Taxus chinensis var. mairei. African Journal of Biotechnology, Bowie, v. 5, n. 10, p. 875-877, 2006.

KUSS, A. V.; KUSS, V. V.; LOVATO, T.; FLORES, M. L. Fixação de nitrogênio e produção de ácido indolacético in vitro por bactérias diazotróficas endofíticas. Pesquisa Agropecuária Brasileira, Brasília, v. 42, n. 10, p. 14591465, 2007.

LANNA FILHO, R.; FERRO, H. M.; PINHO, R. S. C. Controle biológico mediado por Bacillus subtilis. Revista Trópica - Ciências Agrárias e Biológicas, Chapadinha, v. 4, n. 2, p. 12-20, 2010.

LI, J.; STROBEL, G.; SIDHU, R.; HESS, W. M.; FORD, E. J. Endophytic taxol-producing fungi from bald cypress, Taxodium distichurn. Microbiology, Great Britain, v. 142, p. 2223-2226, 1996.

LUZ, J. S.; SILVA, R. L. O.; SILVEIRA, E. B.; CAVALCANTE, U. M. T. Atividade enzimática de fungos endofíticos e efeito na promoção do crescimento de mudas de maracujazeiro-amarelo. Revista Caatinga, Mossoró, v. 19, n. 2, p. 128-134, 2006.

LV, Y.; ZHANG, F.; CHEN, J.; CUI, J.; XING, Y.; LI, X.; GUO, S. Diversity and antimicrobial activity of endophytic Fungi associated with the alpine plant Saussurea involucrate. Biological \& Pharmacentical Bulletin, Tokyo, v. 33, n. 8, p. 1300-1306, 2010.

MARIANO, R. L. R.; SILVEIRA, E. B.; ASSIS, S. M. P.; GOMES, A. M. A.; NASCIMENTO, A. R. P.; DONATO, 
V. M. T. S. Importância de bactérias promotoras de crescimento e de biocontrole de doenças de plantas para uma agricultura sustentável. Anais da Academia Pernambucana de Ciência Agronômica, Recife, v. 1, p. 89-111, 2004.

MARINHO, A. M. R.; MARINHO, P. S. B.; RODRIGUES FILHO, E. Constituintes químicos de Penicillium sp, um fungo endofítico Isolado de Murraya paniculata (Rutaceae). Revista Ciências Exatas e Naturais, Santa Cruz, v. 9, n. 2, p. 189-199, 2007.

MARINHO, A. M. R.; MARINHO, P. S. B.; RODRIGUES FILHO, E. Esteroides produzidos por Penicillium herquei, um fungo endofítico isolado dos frutos de Melia azedarach (Meliaceae), Química Nova, São Paulo, v. 32, n. 7, p. 1710-1712, 2009.

MARINHO, A. M. R.; RODRIGUES-FILHO, E; MOITINHO, M. L. R.; SANTOS, L. S. Biologically active polyketides produced by Penicillium janthinellum isolated as an endophytic fungus from fruits of Melia azedarach. Journal of the Brazilian Chemical Society, São Paulo, v. 16, n. 2, p. 280-283, 2005.

MEDEIROS, M. A.; VILELA, N. J.; FRANÇA, F. H. Eficiência técnica e econômica do controle biológico da traça-do-tomateiro em ambiente protegido. Horticultura Brasileira, Brasília, v. 24, n. 2, p. 180-184, 2006.

MEISTER, B.; KRAUSS, J.;HÄRRI, S.A.; SCHNEIDER, M. V.; MULLER, C. B. Fungal endosymbionts affect aphid population size by reduction of adult life span and fecundity. Basic and Applied Ecology, Jena, v. 7, p. 244252, 2006.

MELO, F. M. P.; FIORE, M. F.; MORAES, L. A. B.; SILVA-STENICO, M. E.; SCRAMIN, S.; TEIXEIRA, M. A.; MELO, I. S. Antifungal compound produced by the cassava endophyte Bacillus pumilus MAIIIM4a. Scientia Agrícola, Piracicaba, v. 66, n. 5, p. 583-592, 2009.

MOMESSO, L. S.; KAWANO, C. Y.; RIBEIRO, P. H.; NOMIZO, A.; GOLDMAN, G. H.; PUPO, M. T. Chaetoglobosinas produzidas por Chaetomium globosum, fungo endofítico associado a Viguiera robusta Gardn. (Asteraceae). Química Nova, São Paulo, v. 31, n. 7, p. 1680-1685, 2008.

MOURA, A. B.; ROMEIRO, R. S.; NEVES, M. C. P. Bioensaio para avaliação massal de actinomicetos antagonistas a Ralstonia solanacearum, em tomateiro. Pesquisa Agropecuária Brasileira, Brasília, v. 33, n. 12, p. 2065-2072, 1998.

MUCCIARELLI, M.; SCANNERINI, S.; BERTEA, C.; MAFFEI, M. In vitro and in vivo peppermint (Mentha piperita) growth promotion by nonmycorrhizal fungal colonization. New Phytologist, Oxford, v. 158, p. 579591, 2003

OKI, Y.; SOARES, N.; BELMIRO, M. S.; CORRÊA JUNIOR, A.; FERNANDES, G. W. Influência dos fungos endofíticos sobre os herbívoros de Baccharis dracunculifolia (Asteraceae). Neotropical Biology and Conservation, Sao Leopoldo, v. 4, n. 2, p. 83-88, 2009.

OLIVEIRA, A.; SANTOS, M. H. M.; SILVEIRA, E. B.; GOMES, A. M. A.; MARIANO, R. L. R. Biocontrole da mancha-aquosa do melão pelo tratamento de sementes com bactérias epifíticas e endofíticas. Horticultura Brasileira, Brasília, v. 24, p. 373-377, 2006.

PASTRE, R.; MARINHO, A. M. R.; RODRIGUESFILHO, E.; SOUZA, A. Q. L.; PEREIRA, J. O. Diversidade de policetídeos produzidos por espécies de Penicillium isoladas de Melia azedarach e murraya paniculata. Química Nova, São Paulo, v. 30, n. 8, p. 1867-1871, 2007.

PEIXOTO NETO, P. A. S.; AZEVEDO, J. L.; ARAÚJO, W. L. Microrganismos endofíticos. Biotecnologia Ciência \& Desenvolvimento, Brasília, v. 29, p. 62-77, 2002.

PEIXOTO NETO, P. A. S.; AZEVEDO, J. L.; CAETANO, L. C. Microrganismos endofíticos em plantas: status atual e perspectivas. Boletin Latinoamericano y del Caribe de Plantas Medicinales y Aromáticas, Santiago, v. 3, n. 4, p. 69-72, 2004.

PHONGPAICHIT, S.; RUNGJINDAMAI, N.; RUKACHAISIRIKUL, V.; SAKAYAROJ, J. Antimicrobial activity in cultures of endophytic fungi isolated from Garcinia species. FEMS Immunology Medical Microbiology, Amsterdam, v. 48, p. 367-372, 2006.

RAMOS, H. P.; BRAUN, G. H.; PUPO, M. T.; SAID, S. Antimicrobial activity from endophytic fungi Arthrinium state of Apiospora montagnei Sacc. and Papulaspora immersa. Brazilian Archives of Biology and Technology, Curitiba, v. 53, n. 3, p. 629-632, 2010.

RAPS, A.; VIDAL, S. Indirect effects of an unspecialized endophytic fungus on specialized plant - herbivorous insect interactions. Oecologia, Berlin, v. 114, p. 541-547, 1998.

ROCHA, R.; LUZ, D. E.; ENGELS, C.; PILEGGI, S. A. V.; JACCOUD FILHO, D. S.; MATIELLO, R. R.; PILEGGI, M. Selection of endophytic fungi from comfrey (Symphytum officinale L.) for in vitro biological control of the phytopathogen Sclerotinia sclerotiorum (Lib.). Brazilian Journal of Microbiology, São Paulo, v. 40, n. 1, p. 73-78, 2009. 
ROSA, L. H.; GONÇALVES, V. N.; CALIGIORNE, R. B.; ALVES, T. M. A.; RABELLO, A.; SALES, P. A.; ROMANHA, A. J.; SOBRAL, M. E. G.; ROSA, C. A.; ZANI, C. L. Leishmanicidal, trypanocidal, and cytotoxic activities of endophytic fungi associated with bioactive plants in Brazil. Brazilian Journal of Microbiology, São Paulo, v. 41, p. 420-430, 2010.

RUBINI, M. R.; SILVA-RIBEIRO, R. T.; POMELLA, A. W. V.; MAKI, C. S.; ARAÚJO, W. L.; SANTOS, D. R.; AZEVEDO, J. L. Diversity of endophytic fungal community of cacao (Theobroma cacao L.) and biological control of Crinipellis perniciosa, causal agent of Witches' Broom Disease. International Journal of Biological Sciences, Bethesda, v. 1, p. 24-33, 2005.

RYAN, R. P.; GERMAINE, K.; FRANKS, A.; RYAN, D. J.; DOWLING, D. N. Bacterial endophytes: recent developments and applications. FEMS Microbiology Letters, Amsterdam, v. 278, p. 1-9, 2008.

SANTOS, L. S.; OLIVEIRA, M. N.; GUILHON, G. M. S. P.; SANTOS, A. S.; FERREIRA, I. C. S.; LOPESJÚNIOR, M. L.; ARRUDA, M. S. P.; SAILVA, M. N.; SOUZA FILHO, A. P. S.; RODRIGUES FILHO, E.; OLIVEIRA, M. C. F. Potencial herbicida da biomassa e de substâncias químicas produzidas pelo fungo endofítico Pestalotiopsis guepinii. Planta Daninha, Viçosa, v. 26, n. 3, p. 539-548, 2008.

SHIOMI, H. F.; MELO, I. S.; MINHONI, M. T. A. Seleção de bactérias endofíticas com ação antagônica a fitopatógenos. Scientia Agrária, Curitiba, v. 9, n. 4, p. 535-538, 2008.

SHIOMI, H. F.; SILVA, H. S. A.; MELO, I. S.; NUNES, F. V.; BETTIOL, W. Bioprospecting endophytic bacteria for biological control of coffee leaf rust. Scientia Agrícola, Piracicaba, v. 63, n. 1, p. 32-39, 2006.

SILVA, G. H.; OLIVEIRA, C. M.; TELES, H. L.; BOLZANI, V. S.; ARAUJO, A. R.; PFENNING, L. H.; YOUNG, M. C. M.; COSTA-NETO, C. M.; HADDAD, R.; EBERLIN, M. N. Citocalasinas produzidas por Xylaria sp., um fungo endofítico de Piper aduncum (piperaceae). Química Nova, São Paulo, v. 33, n. 10, p. 2038-2041, 2010.

SILVA, G. H.; TELES, H. L.; TREVISAN, H. C.; BOLZANI, V. S.; YOUNG, M. C. M.; PFENNING, L. H.; EBERLIN, M. N.; HADDAD, R.; COSTA-NETO, C. M.; ARAÚJO, A. R. New bioactive metabolites produced by Phomopsis cassiae, an endophytic fungus in Cassia spectabilis. Journal of the Brazilian Chemical Society, São Paulo, v. 16, n. 6B, p. 1463-1466, 2005.

SILVA, J. R. C.; SOUZA, R. M.; ZACARONE, A. B.; SILVA, L. H. C. P.; CASTRO, A. M. S. Bactérias endofíticas no controle e inibição in vitro de Pseudomonas syringae $p v$ tomato, agente da pinta bacteriana do tomateiro. Ciência e agrotecnologia, Lavras, v. 32, n. 4, p. 1062-1072, 2008.

SILVA, R. L. O.; LUZ, J. S.; SILVEIRA, E. B.; CAVALCANTE, U. M. T. Fungos endofíticos em Annona spp.: isolamento, caracterização enzimática e promoção do crescimento em mudas de pinha (Annona squamosa L.) Acta Botânica Brasílica, São Paulo, v. 20, n. 3, p. 649-655, 2006.

SOUSA, C. S.; SOARES, A. C. F.; GARRIDO, M. S. Produção de mudas de tomateiro em substrato orgânico inoculado e incubado com estreptomicetos. Bragantia, Campinas, v. 68, n. 1, p. 195-203, 2009.

SOUZA, A. Q. L.; SOUZA, A. D. L.; ASTOLFI FILHO, S.; BELÉM PINHEIRO, M. L.; SARQUIS, M. I. M.; PEREIRA, J. O. Atividade antimicrobiana de fungos endofíticos isolados de plantas tóxicas da amazônia: Palicourea longiflora (aubl.) rich e Strychnos cogens bentham. Acta Amazônica, Manaus, v. 34, n. 2, p. $185-$ 195, 2004.

SOUZA, M. L. Utilização de microrganismos na agricultura. Biotecnologia, Piracicaba, n. 21, p. 28-31, 2001.

SREEKANTH, D.; SYED, A.; SARKAR, S.; SARKAR, D.; SANTHAKUMARI, B.; AHMAD, A.; KHAN, M. I. Production, purification, and characterization of Taxol and 10-DABIII from a new Endophytic Fungus Gliocladium sp. Isolated from the Indian Yew Tree, Taxus baccata. Journal of Microbiology and Biotechnology, Oxford, v. 19, n. 11, p. 1342-1347, 2009.

STAMFORD, T. L. M.; ARAÚJO, J. M.; STAMFORD, N. P. Atividade enzimática de microrganismos isolados do jacatupé (Pachyrhizus erosus L. Urban). Ciência e Tecnologia de Alimentos, Campinas, v. 18, n. 4, 1998.

STIERLE, A.; STROBEL, G.; STIERLE, D. Taxol and taxane production by taxomyces andreanae an endophytic fungus of Pacific yew. Science, New York, v. 260, p. 214 216, 1993.

STROBEL, G. A.; DIRKSE, E.; SEARS, J.; MARKWORTH, C. Volatile antimicrobials from Muscodor albus, a novel endophytic fungus. Microbiology, Great Britain, v. 147, p. 2943-2950, 2001.

STROBEL, G. A.; MILLER, R. V.; MARTINEZMILlER, C.; CONDRON, M. M.; TEPLOW, D. B.; HESS, W. M. Cryptocandin, a potent antimycotic from the endophytic fungus Cryptosporiopsis cf. quercina. Microbiology, Great Britain, v. 145, p. 1919-1926, 1999.

STROBEL, G.; DAISY, B. Bioprospecting for microbial 
endophytes and their natural products. Microbiology and Molecular Biology Reviews, New York, v. 67, n. 4, p. 491-502, 2003.

STROBEL, G.; YANG, X.; SEARS, J.; KRAMER, R.; SIDHU, R. S.; HESS, W. M. Taxol from Pestalotiopsis microspora, an endophytic fungus of Taxus wallachiana. Microbiology, Great Britain, v. 142, p. 435-440, 1996.

STURTZ, A. V.; MATHESON, B. G. Populations of endophytic bacteria which influence host-resistance to Erwinia-induced bacterial soft rot in potato tubers. Plant Soil, Dordrecht, v. 184, n. 2, p. 265-271, 1996.

TAKAHASHI, J. A.; LUCAS, E. M. F. Ocorrência e diversidade estrutural de metabólitos fúngicos com atividade antibiótica. Química Nova, São Paulo, v. 31, n. 7, p. 1807-1813, 2008.

TEIXEIRA, M. A.; MELO, I. S.; VIEIRA, R. F.; COSTA, F. E. C.; HARAKAVA, R. Microrganismos endofíticos de mandioca de áreas comerciais e etnovariedades em três estados brasileiros. Pesquisa Agropecuária Brasileira, Brasília, v. 42, n. 1, p. 43-49, 2007.

TEJESVI, M. V.; NALINI, M. S.; MAHESH, B.; PRAKASH, H. S.; KINI, K. R.; SHETTY, H. S.; SUBBIAH, V. New hopes from endophytic fungal secondary metabolites. Boletín de la Sociedad Química de México, Querétaro, v. 1, n. 1, p. 19-26, 2007.

VARMA, A.; VERMA, S.; SUDAH, S. N.; FRANKEN, P. Piriformospora indica, a cultivable plant-growthpromoting root endophyte. Applied and Environmental Microbiology, Washington, v. 65, p. 2741-2744, 1999.

VERZIGNASSI, J. R.; HOMECHIN, M.; VIDA, J. B. Microrganismos endofíticos. Semina: Ciências Agrárias, Londrina, v. 17, n. 1, p. 93-98, 1996.

VISALAKCHI, S.; MUTHUMARY, J. Taxol (anticancer drug) producing endophytic fungi: an overview. International Journal of Pharma and Bio Sciences, India, v. 1, n. 3, p. 1-9, 2010.

WANG, J.; LI, G.; LU, H.; ZHENG, Z.; HUANG, Y.; SU, W. Taxol from Tubercularia sp. strain TF5, an endophytic fungus of Taxus mairei. FEMS Microbiology Letters, Amsterdam, v. 193, p. 249-253, 2000.

Recebido em 21 de março de 2011 - Received on March 21, 2011

Aceito em 17 de agosto de 2011 - Accepted on August 17, 2011 
